\title{
The Optimum Distance of Lift-Off Height on Different Test Material's Thickness by using Eddy Current Testing Technique
}

\author{
Fauziah Sulaiman, Salmia Santa, Elnetthra Folly Eldy
}

\begin{abstract}
The Eddy current testing (ECT) technique is one of the non-destructive testing (NDT) techniques which is sensitive to the unintended signal such as lift-off (LO) height effect. The output voltage of signal defects with different thicknesses of test materials (i.e., Copper, Brass and Magnesium Alloy) can be determined from the optimum distance of LO height of the ECT technique. Previously, an established frequency was determined for these particular materials (i.e., Copper $=(5.00-5.25) \mathrm{MHz}$, Brass $=(4.75-5.25) \mathrm{MHz}$ and Magnesium Alloy= $(4.75-5.00) \mathrm{MHz})$. The frequency then generated the established voltage signal of the ECT technique. The acquired optimum distance of $\mathrm{LO}$ height for these materials is approximately $2 \mathrm{~mm}$. The findings from this established technique indicated that the determined optimum distance of LO height can find the output voltage signal of the defects as well as to detect the thicknesses.
\end{abstract}

Keywords: ECT Technique, Lift-off Optimum Distances, Non Destructive Test (NDT).

\section{INTRODUCTION}

The eddy current testing (ECT) technique is broadly used in several industrial sectors as to test and assess the integrity of material and solid structure. Principally testing of metallic material used in ECT for the identification forms of defects [1]. ECT technique has become a handy tool in non-destructive evaluation for test materials in different geometries using developed coil probe to accommodate increasingly complex material geometries [2]. Thus, ECT technique allows the measurement of the material's internal structural condition such as surface or subsurface defects to identification and determination of the defect position and geometric parameters including the thickness of test material products [3]. Once eddy current (EC) detects defects in the material, it learns that EC signals can be detected and used to describe the defects responses. There are quite a few tests and measurements that can be carried out using the ECT technique that is ahead of the other NDT techniques. This include measurements of materials thickness. This is a useful tool to recognize defect exposure and other characteristics of materials. For instance,

Revised Manuscript Received on September 20, 2020.

* Correspondence Author

Fauziah Sulaiman*, Teaching Physics (Thermodynamics and Statistical Physic) in Universiti Malaysia Sabah.

Salmia Santa, Faculty of Science and Natural Resources, Universiti Malaysia Sabah

Elnetthra Folly Eldy, Lecturer, Universiti Malaysia Sabah

(C) The Authors. Published by Blue Eyes Intelligence Engineering and Sciences Publication (BEIESP). This is an open access article under the CC BY-NC-ND license (http://creativecommons.org/licenses/by-nc-nd/4.0/) the application of ECT technique used on aircraft fuselage skins and tube walls that used as heat exchangers [4],[5]. Normally, commercially available eddy current testing (ECT) techniques have limitations to detect defects of material that exceed more than $5 \mathrm{~mm}$ of thickness. Therefore, suitable for detecting subsurface defects using lower excitation current of the ECT [6]. Some previous research report there are practical parameters for how far we can go deep into the materials yet still perform a successful ECT. Basically, 0.2 inch range is being used as a typical value for effective penetration depth (which is, $\delta_{\text {eff }}=3 \delta$ ). Meaning, when the material's thickness decreases in detection of several skin depths, a significant amount of the magnetic field penetrates the material. In addition, a material thickness of the magnetic field that induces the eddy currents has plummeted to a smaller amount than $1 \%$ of its value at the material surface [7]. As regards Angani et al.,[8] found that the material thickness increased and the output signal decreased due to the change in the frequency of the observed magnetic field signal.

\section{EDDY CURRENT TESTING}

The eddy current testing (ECT) technique is exercised in innumerable of industries to find and detect defects, weaknesses, imperfections, flaws or cracks. Fundamentally, the technique is expended to estimate the internal structural state of solid and material, the surface imperfection and subsurface flaws, spot the fatigue fractures, and determine the crack position and the geometrical parameters such as the thickness of the metal sheet or dielectric coating on metal products [3]. Hence, it's discover when eddy current meets a gap in the test material the variation in the eddy current density can be detected and be exploited to characterize the gap causing that change. There are various of inspections and measurements may be performed with the ECT that are further than the scope of other NDT techniques. This is including measurements of thin materials such as sheet stock and tubing. This tool is very handy for detecting corrosion damage and other destruction that causes a thinning of the material. For instance, the measurements used on aircraft fuselages skins and in the walls of tubing in assemblies such as heat exchangers. Additionally, the ECT is also applied to determine the thickness of paints and other coatings on materials. The ECT equipment and probes can be acquiring in many of configuration like computer system for data manipulation,

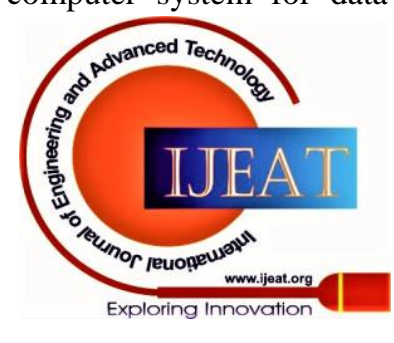




\section{The Optimum Distance of Lift-Off Height on Different Test Material's Thickness by using Eddy Current Testing Technique}

conductivity tester, eddy scopes, signal processing software, impedance analyzer and a few portable scanning for special applications. Thus, the test parameters and the probe design must be established with the good knowledge of the imperfections, defects and cracks that need to be detected to make the measurements is valid and could be implemented.

\section{The LO (Lift-Off)}

The lift-off (LO) of ECT technique defines as impedance change that happens when there is variation of gap distance between the test piece and the inspection coil probe. The vary of LO distance will affect the analysis result, since the large LO noise changes the signal phase much from the probe. The signal phase can hardly be used to detect defect, flaws or imperfection. Means that the gap between the test piece and the inspection coil probe must be as stavle as possible to prevent $\mathrm{LO}$ effect. However, since in many applications, the effect considered as a noise source and it is an undesired variable in defect detection, so determine an appropriate LO effect will contribute to optimizing the application of the coil design and the sensor array for certain instrument. The calibration signal of LO effect method shown as Figure 1. The LO variation is critical for the mutual distance between the test piece and the inspection coil probe under inspection because it leads to change of the eddy currents distribution inside the material or test piece and hence a variation of the signal received by the eddy current sensor [1]. This is happen when variations of $\mathrm{LO}$ triggered by dissimilar attribute of coating thickness and defects of sample surfaces. In addition, operator's movements while doing inspection also might contribute to the variation of signal. Throughout impedance analysis will carry out the signal indication that appropriate with the probe's instrument [9].

\section{METHODOLOGY}

The optimum distance of LO height for ECT technique used on two types of testing which are; i. material artificial defect and, ii. various thickness. The output is the voltage signals. This is to verify that the optimum distance of LO height from the ECT instrument can be used for the testing.

The setup for the LO height measurement was performed as shows in Figure 1. LO distance is the distance between test material and coil probe. The difference of $\mathrm{LO}$ height of the test material was tested when the coil probe brought close to the surface of the test material, the output voltage signal observed varied by the variation of LO height. The coil probe is the circular air-cored coil used to sense the test material.

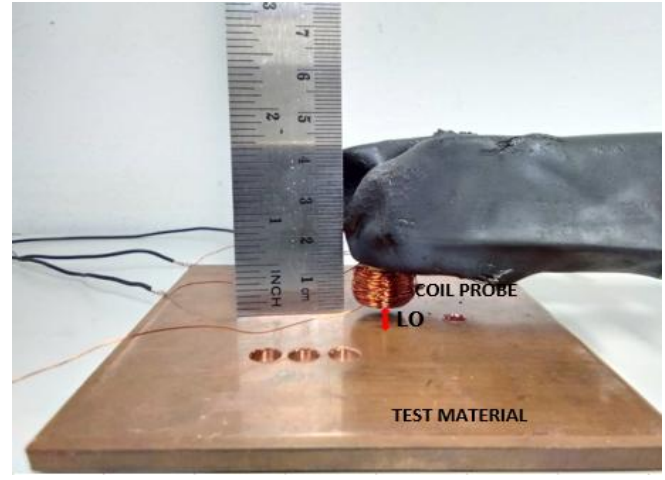

Fig.1. Lift-Off (LO) Measurement
The test materials used are copper, brass and magnesium alloy with three (3) different thickness respectively; i.e., 1.5 $\mathrm{mm}, 3.0 \mathrm{~mm}$ and $5.0 \mathrm{~mm}$. Each of the test materials were tested with different artificial defect sizes; $7.0 \mathrm{~mm}, 14.0 \mathrm{~mm}$ and $21.0 \mathrm{~mm}$. In this research, copper $(\mathrm{Cu})$, brass and magnesium alloy (Mg Alloy) with dimensions of $100 \mathrm{~mm} x$ $100 \mathrm{~mm}$ were tested for defects consisting of three different thicknesses which are $1.5 \mathrm{~mm}, 3.0 \mathrm{~mm}$ and $5.0 \mathrm{~mm}$. Each of these different thickness materials were installed with artificial defects (e.g., $7.0 \mathrm{~mm}, 14.0 \mathrm{~mm}$ and $21.0 \mathrm{~mm}$ ). Figure 2 shows one of the test materials which is copper with three (3) different thicknesses.

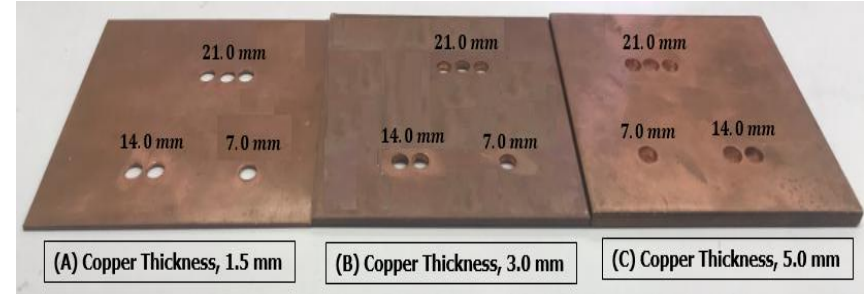

Fig. 2. Picture of artificial defects of copper material with different thicknesses (i.e $1.5 \mathrm{~mm}, 3.0 \mathrm{~mm}$ and $5.0 \mathrm{~mm}$ ).

In this testing, copper $(\mathrm{Cu})$, brass and magnesium alloy (Mg Alloy) as shows in Table 1 were selected as the testing material, this is due to readily availability of these materials and extensively used in industries such as pipe manufacturing, decoration and transportation. Other than that, the characterization of permeability and conductivity of these materials suitable for testing by eddy current testing (ECT). According to Ghanei et al., [10] stated that the output signals increased as increasing the magnetic permeability will increase in the self-inductance which in turn, results in increasing the induction resistance.

Table 1. The testing material

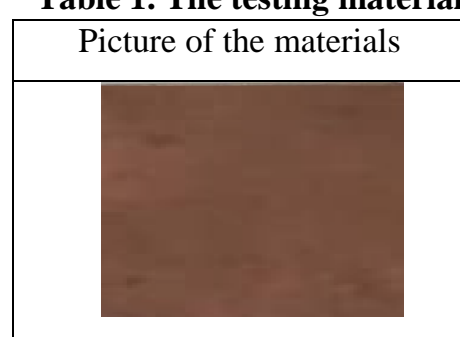

a) Copper

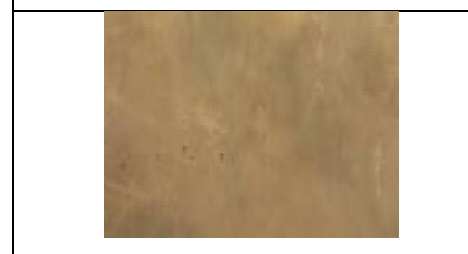

b) Brass

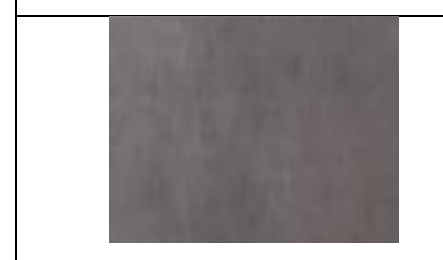

c) Magnesium alloy

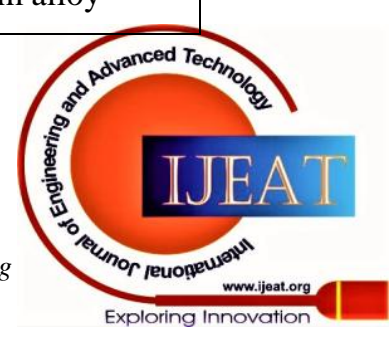




\section{EXPERIMENTAL RESULT AND COMPARISON}

The measurement validation of eddy current testing (ECT) technique consists of two essential parameters consideration. First is the excitation signal from an operating frequency of the ECT technique. Then, the ECT technique used to assess the selected testing material varied by variation lift-off (LO) height from $0 \mathrm{~mm}$ to $5 \mathrm{~mm}$ with increment of every $1 \mathrm{~mm}$.

These parameters were assessed by the coil probe and finally the output voltage signal of ECT consists of detection signal of defects and different thickness (e.g., $1.5 \mathrm{~mm}, 3.0$ $\mathrm{mm}$ and $5.0 \mathrm{~mm}$ ) of the test materials that obtained from the ECT technique.

First parts of this research experiment were the setup of an operating frequency. The operating frequency was excited by using an exciter-receiver coil probe. The coil probe produced a primary magnetic field which drives constant current at fixed coil locations. The second magnetic field was then produced when the coil probe brought close to the testing material. Therefore, an electromagnetic field was created over a specific frequency range used between $1.0 \mathrm{MHz}$ to 6.0 $\mathrm{MHz}$ for the ECT technique. These range of operating frequencies testing cover for all the testing materials [e.g., copper (Cu), brass and magnesium alloy (Mg Alloy)] with different thickness (e.g., $1.5 \mathrm{~mm}, 3.0 \mathrm{~mm}$ and $5.0 \mathrm{~mm}$ ). As the result the operating frequency for all three materials are: copper $=(5.00-5.25) \mathrm{MHz}$, brass $=(4.75-5.25) \mathrm{MHz}$ and magnesium alloy $=(4.75-5.00) \mathrm{MHz})$ respectively.

Figure 3 shows the combine graphs of output voltage signal of various thickness test material for copper, brass and magnesium alloy. The result showed a decrease in the output voltage signal as the thickness of the test material was increased by $2 \mathrm{~mm}$ at the same LO height. This similar study by regards Angani et al., [8] concluded that the material thickness increased and the output voltage signal decreased due to the changing magnetic field signal between coil probe and the material testing.

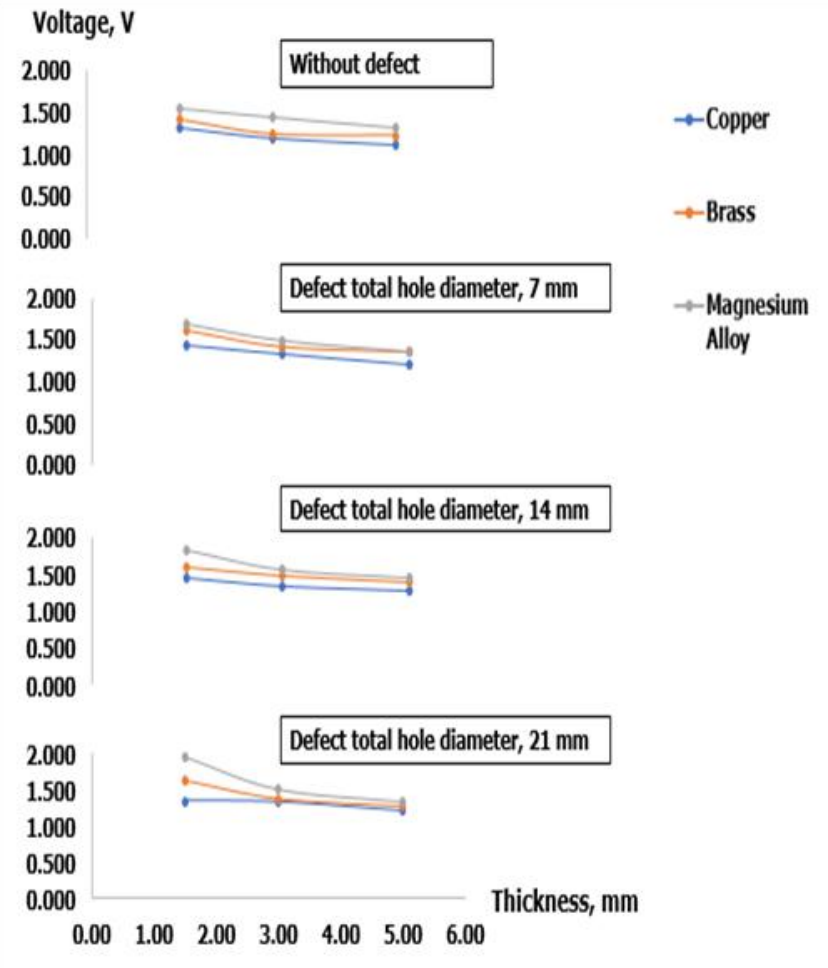

Fig. 3. Output voltage vs thickness of different defect of total hole diameter for each testing material (copper, brass and magnesium alloy) at frequency $5.250 \mathrm{MHz}$ and LO height is $\mathbf{2} \mathbf{~ m m}$.

Graph in Figure 4 displayed the combine graph of output voltage signals for three different thickness of copper mounted with different defects, then the result of the output voltage signal based on the different LO heights. As a result, the value of the output voltage for defect detection was changed as larger of the defect diameter and LO height at 3 $\mathrm{mm}$ and above showed that the output voltage signal was constant, which means if the maximum distance of LO height for copper was about $2 \mathrm{~mm}$.

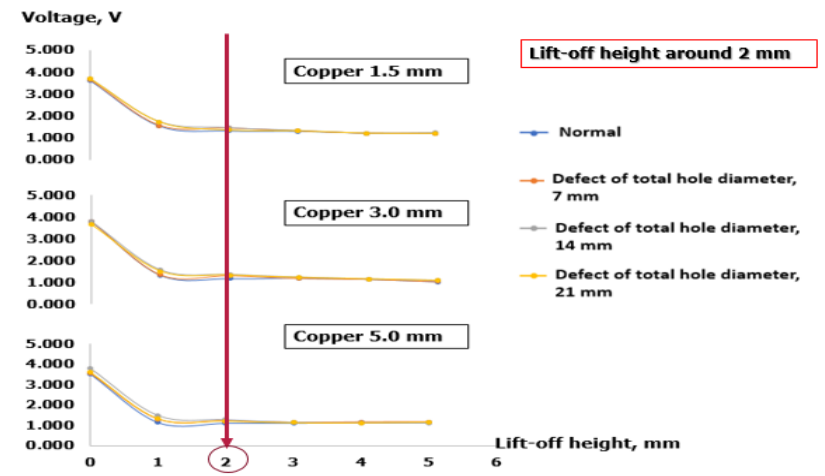

Fig. IV: Graph of output voltage vs LO height at frequency 5.25 MHz for different thickness of copper (e.g., $1.5 \mathrm{~mm}, 3.0 \mathrm{~mm}$ and $5.0 \mathrm{~mm}$ ) with a variation of defect hole diameter (e.g., $7.0 \mathrm{~mm}, 14.0 \mathrm{~mm}$ and 21.0 mm).

Figure 5 shows the combine graphs of the output voltage brass with three types of thicknesses and maximum distance of LO height is $2 \mathrm{~mm}$. Meanwhile, Figure 6, shows the output voltage for magnesium alloy and maximum distance of LO height is $2 \mathrm{~mm}$. Hence, it is concluded from this finding that the relevant LO height was around $2 \mathrm{~mm}$, which is obtained from the obvious output voltage signal of the testing. This is similar with Huang et al., [5] finding which stated that when the LO height exceeded $3 \mathrm{~mm}$, the noise level overruns the amplitude of the signal caused the signal response to be weakened.

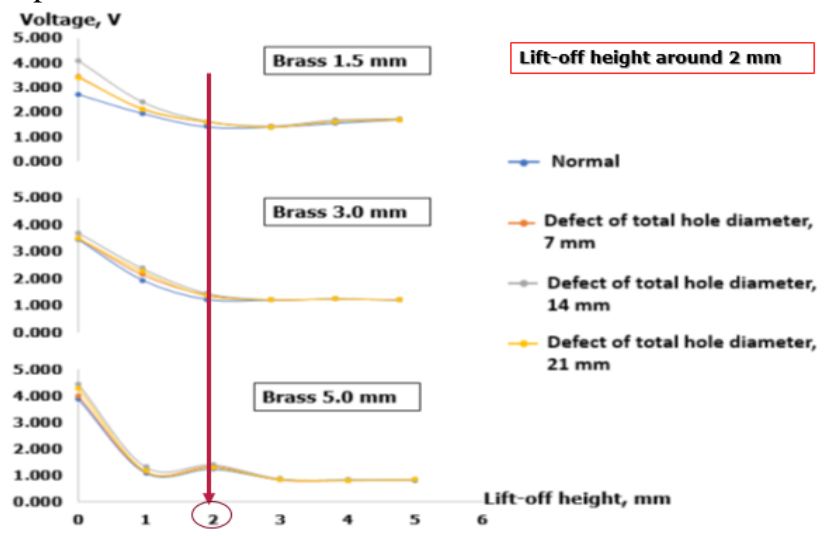

Fig. 5: Graph of output voltage vs lift-off (LO) height at frequency $5.25 \mathrm{MHz}$ for different thickness of brass (e.g., $1.5 \mathrm{~mm}, 3.0 \mathrm{~mm}, 5.0 \mathrm{~mm}$ ) with a variation of defect hole diameter (e.g., 7.0 mm, $14.0 \mathrm{~mm}, 21.0 \mathrm{~mm}$ ).

Published By:

Blue Eyes Intelligence Engineering and Sciences Publication (C) Copyriaht: All riahts reserved.

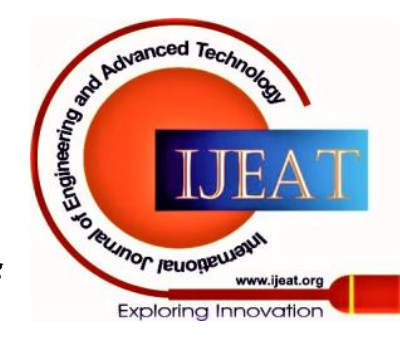




\section{Testing Technique}

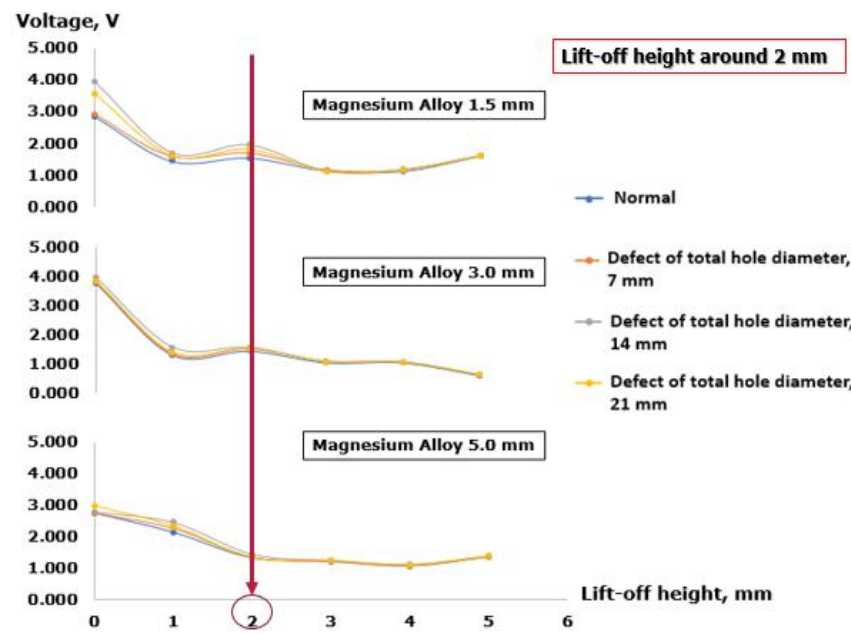

Figure 6: Graph of output voltage vs lift-off height at frequency 5.25 MHz for different thickness of magnesium alloy (e.g., $1.5 \mathrm{~mm}, 3.0 \mathrm{~mm}, 5.0 \mathrm{~mm}$ ) with a variation of defect hole diameter (e.g., $7.0 \mathrm{~mm}, 14.0 \mathrm{~mm}, 21.0 \mathrm{~mm}$ ).

\section{CONCLUSION}

Based on the analysis result, it is possible to perform assessment of varies test material thickness (e.g., $1.5 \mathrm{~mm}, 3.0$ $\mathrm{mm}$ and $5.0 \mathrm{~mm}$ ) throughout the optimum distance of the lift-off (LO) height. The distance of LO height can affect the output voltage signals and therefore can cause misinterpretation of the defects signal on test materials (e.g., copper, brass and magnesium alloy). The experimental test results show that the optimum distance of LO height is approximately $2 \mathrm{~mm}$. Subsequent research need to be done to extend the methods that consider multiple layer structures such as coatings on nonmagnetic and magnetic materials to improve the defect detection.

\section{ACKNOWLEDGMENT}

This study was supported by Universiti Malaysia Sabah under research grant:

1. SLB0148-2017

2. SBK 0280-SG-2016, and

3. UMS Great: GUG0018-SG-M-1/2016

\section{REFERENCES}

1. Ricci, M., Silipigni, G., Ferrigno, L., Laracca, M. \& Adewale, I.D. 2017 Evaluation of the lift-off robustness of eddy current imaging techniques. Journal of NDT\&E International 85:43-52. H. Poor, An Introduction to Signal Detection and Estimation. New York: Springer-Verlag, 1985, ch. 4.

2. Klein, G., Morelli, J., \& Krause, T. W. (2018). Analytical model of the eddy current response of a drive-receive coil system inside two concentric tubes. NDT and E International, 96(June 2017), 18-25. https://doi.org/10.1016/j.ndteint.2018.03.003.

3. Egorov, A., Polyakov, V., Salita, S., Kolubaev, A., Psakhie, G., Chernyavskii, G., \& Vorobei, V. (2015). Inspection of aluminium alloys by a multi-frequency eddy current method. Defence Technology, 11(2), 99-103. https://doi.org/10.1016/j.dt.2014.12.002

4. Yuan, X., Li, W., Chen, G., Yin, X., Ge, J., Yang, W., ... Ma, W. (2018). Inner circumferential current field testing system with TMR sensor arrays for inner- wall cracks inspection in aluminum tubes. Measurement: Journal of the International Measurement Confederation, 122(March)

232-239. https://doi.org/10.1016/j.measurement.2018.03.035.

5. Huang, S., Zhao, W., Zhang, Y. \& Wang, S. 2009. Study on the lift-off effect of EMAT. Journal of Sensors and Actuators A 153:218-221.

6. Soni, A. K., Thirunavukkarasu, S., Sasi, B., Rao, B. P. C., \& Jayakumar, T. (2015). Development of a high-sensitivity eddy current instrument for the detection of sub-surface defects in stainless steel plates. Insight:
Non-Destructive Testing and Condition Monitoring, 57(9), 508-512. https://doi.org/10.1784/insi.2015.57.9.508.

7. Shull, P.J. (2002). Nondestructive evaluation: theory, techniques, and applications. CRC press.

8. Angani, C. S., Ramos, H. G., Ribeiro, A. L., Rocha, T. J., \& Prashanth, B. (2015). Transient eddy current oscillations method for the inspection of thickness change in stainless steel. Sensors and Actuators, A Physical, 233, 217-223. https://doi.org/10.1016/j.sna.2015.07.003.

9. Li, X., Yin, W., Liu, Z., Withers, P.J., \& Peyton, A. J. (2008) Characterization of carbon fibre reinforced composite by means of non-destructive Eddy Current Testing and FEM modeling. 17 Th World Conference on Nondestructive Testing, (January), 3-9.

10. Ghanei, S., Kashefi, M., \& Mazinani, M. (2013). Eddy current nondestructive evaluation of dual phase steel. Materials and Design, $\mathbf{5 0}$ 491-496. https://doi.org/10.1016/j.matdes.2013.03.040

\section{AUTHORS PROFILE}

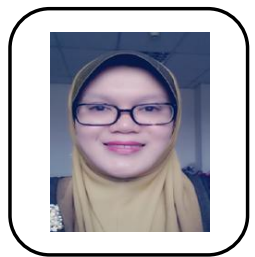

Fauziah Sulaiman was graduated from Universit Sains Malaysia in 2002 with BSc. in Pure Physics and MA in Physics Education/Educational Technology. On 2011, she finishes her $\mathrm{PhD}$ in Physics Education from the University of Waikato, New Zealand and currently teaching Physics (Thermodynamics and Statistical Physic) in Universiti Malaysia Sabah. Her current research work mainly about student-centered learning, problem-based learning in a higher education institution, science education in higher learning and non-destructive testing (NDT) in Physics. She is also a member of MyPBL and her latest work of publication is Optimal Frequency Design of Eddy Current Testing for Copper, Brass and Magnesium Alloy Metal with Difference Thickness published in the Global Journal of Engineering Science and Research Management. Another latest paper by Fauziah is The Effectiveness of Practical Work in Physics to Improve Students; Academic Performances published in International Journal of Social Sciences.

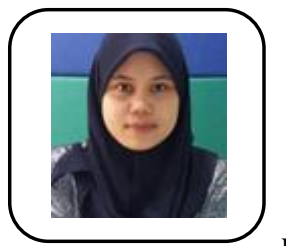

Salmia Santa is a student at the Faculty of Science and Natural Resources, Universiti Malaysia Sabah (UMS). She just done with her viva voce and currently doing corrections on her thesis. She is taking Master of Science in Physic with Electronics Program. She was graduated from UMS for her BSc. of Physic With Electronics as well in 2011. Her current research work in MSc is about Non-destructive Testing (NDT) by using an Eddy Current Testing (ECT). Her latest work of publication is Optimization Frequency for Different Lift-off on Aluminium Using Eddy Current Testing (ECT) Technique was published in Transaction on Science and Technology (2019). She also published a paper in IJEAT under the title "Eddy Current Testing Technique to Detect Imperfection Surface for Different Lif-off Value on Copper Metal" co-author by the same team with Fauziah and Elnetthra.

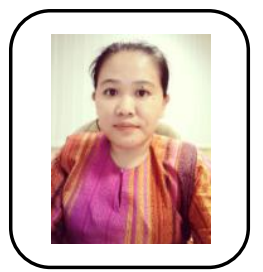

EInetthra Folly Eldy is currently a lecturer in Universiti Malaysia Sabah teaching Physics for pre-university students. She graduated from Universiti Malaysia Sabah for her BSc in Physics with Electronics in 2011 and her MSc in Educational Technology on 2015. Her current interest in research is about student-centered learning, problem-based learning in a higher education institution and blended learning in higher learning. Her latest work is entitled Inverted Classroom Improves Pre-University Students Understanding On Basic Topic Of Physics: The Preliminary Study published in the Journal of Technology and Science Education, Optimisation Frequency for Different Lift off on Aluminium using Eddy Current Testing (ECT) Technique published in Transaction on Science and Technology both in 2019.

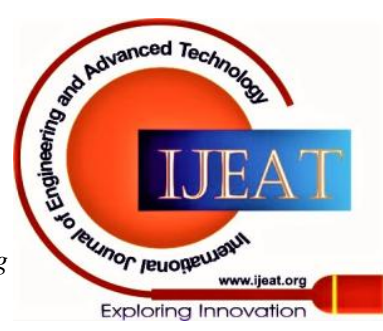

